\title{
Cross-regulation between Notch and p63 in keratinocyte commitment to differentiation
}

\author{
Bach-Cuc Nguyen, ${ }^{1}$ Karine Lefort ${ }^{2}$ Anna Mandinova, ${ }_{1}^{1}$ Dario Antonini ${ }^{3}$ Vikram Devgan, ${ }^{1}$ \\ Giusy Della Gatta, ${ }^{3}$ Maranke I. Koster, ${ }^{4}$ Zhuo Zhang, ${ }^{1}$ Jian Wang, ${ }^{1}$ Alice Tommasi di Vignano, ${ }^{1}$ \\ Jan Kitajewski, ${ }^{5}$ Giovanna Chiorino, ${ }^{6}$ Dennis R. Roop ${ }^{4}$ Caterina Missero, ${ }^{3,7,9}$ and \\ G. Paolo Dotto ${ }^{1,2,7,8}$ \\ ${ }^{1}$ Cutaneous Biology Research Center, Massachusetts General Hospital, Charlestown, Massachusetts 02129, USA; \\ ${ }^{2}$ Department of Biochemistry, University of Lausanne, Epalinges $1066 \mathrm{CH}$, Switzerland; ${ }^{3}$ Telethon Institute of Genetics and \\ Medicine (TIGEM), 80131 Naples, Italy; ${ }^{4}$ Department of Molecular and Cellular Biology, Baylor College of Medicine, \\ Houston, Texas 77030, USA; ${ }^{5}$ Department of Pathology, Department of Obstetrics and Gynecology, and Irving Cancer \\ Research Center, Columbia University Medical Center, New York, New York 10032, USA; ${ }^{6}$ Laboratory of Cancer \\ Pharmacogenomics, Fondo "Edo Tempia," 13900 Biella, Italy
}

Notch signaling promotes commitment of keratinocytes to differentiation and suppresses tumorigenesis. p63, a p53 family member, has been implicated in establishment of the keratinocyte cell fate and/or maintenance of epithelial self-renewal. Here we show that p63 expression is suppressed by Notch1 activation in both mouse and human keratinocytes through a mechanism independent of cell cycle withdrawal and requiring down-modulation of selected interferon-responsive genes, including IRF7 and/or IRF3. In turn, elevated p63 expression counteracts the ability of Notch1 to restrict growth and promote differentiation. p63 functions as a selective modulator of Notch1-dependent transcription and function, with the Hes-1 gene as one of its direct negative targets. Thus, a complex cross-talk between Notch and p63 is involved in the balance between keratinocyte self-renewal and differentiation.

[Keywords: Keratinocyte; stem cells; Notch; p63; interferon-responsive genes; HES/HERP family members]

Supplemental material is available at http://www.genesdev.org.

Received December 27, 2005; revised version accepted February 10, 2006.

Normal tissue homeostasis is determined by a complex interplay between developmental signals and other cell regulatory pathways. Notch cell surface receptors and their ligands belonging to the Delta and Serrate/Jagged families play a crucial role in cell fate determination and differentiation, functioning in a cell- and context-specific manner (Artavanis-Tsakonas et al. 1999). In mammalian cells, Notch activation is generally thought to maintain stem cell potential and inhibit differentiation, thereby promoting carcinogenesis (Artavanis-Tsakonas et al. 1999|. However, in specific cell types such as keratinocytes, increased Notch activity causes exit from the cell cycle and commitment to differentiation (Lowell et al. 2000; Rangarajan et al. 2001; Nickoloff et al. 2002),

\footnotetext{
${ }^{7}$ These authors contributed equally to this work. Corresponding authors.

${ }^{8}$ E-MAIL gdotto@partners.org; FAX 41-21-692-5705.

${ }^{9}$ E-MAIL missero@tigem.it; FAX 39-081-6132351.

Article and publication are at http://www.genesdev.org/cgi/doi/10.1101/ gad.1406006.
}

whereas down-modulation or loss of Notch1 function promotes carcinogenesis (Talora et al. 2002; Nicolas et al. 2003).

In the human epidermis, localized expression of the Notch-ligand Delta in putative "stem cells" has been proposed to induce commitment of neighboring Notch1expressing keratinocytes to a "transit-amplifying" phenotype, through a negative feedback mechanism of lateral inhibition (Lowell et al. 2000). On the other hand, in both mouse and human epidermis, Jagged $1 / 2$, Notch 1 , and Notch2 are coexpressed in differentiating keratinocytes of the supra-basal layers, consistent with a positive feedback loop between these molecules that serves to reinforce and synchronize Notch activation with differentiation (Luo et al. 1997; Rangarajan et al. 2001; Nickoloff et al. 2002).

The best characterized "canonical" pathway of Notch activation involves proteolytic cleavage and translocation of the cytoplasmic domain of the receptor to the nucleus, where it associates with the DNA-binding protein RBP-Јк (CBF-1, CSL), converting it from a repressor 
into an activator of transcription (Mumm and Kopan 2000; Lai 2002). However, direct binding of Notch to a second ancillary protein, Mastermind-like 1 (MAML-1) is required for elevated levels of RBP-dependent transcriptional activation through recruitment of further transcription coactivators such as p300 (Petcherski and Kimble 2000; Wu et al. 2000; Oswald et al. 2001). Transcriptional repressors of the HES (Hairy Enhancer of Split)/HERP (HES-related repressor protein) family are well-characterized direct targets of Notch/RBP-Jк activation (Davis and Turner 2001; Iso et al. 2003). In mouse keratinocytes, the gene for the cyclin/CDK inhibitor $\mathrm{p} 21^{\text {WAF1/Cip } 1}$ is also induced by the Notch/RBP-Jк complex through both a direct and indirect mechanism (Rangarajan et al. 2001; Mammucari et al. 2005), with p $21^{\text {WAF1/Cip } 1}$ functioning downstream of Notch, as a negative transcriptional regulator of Wnt4 expression (Devgan et al. 2005). Notch activation also exerts effects on other pathways important to keratinocyte growth and differentiation; it induces NF-кB (Nickoloff et al. 2002) and inhibits AP-1 (Chu et al. 2002; Talora et al. 2002) and $\beta$-catenin signaling (Nicolas et al. 2003; Devgan et al. 2005).

While Notch activation restricts the proliferative potential of keratinocytes and promotes differentiation, p63, a close homolog of the p53 tumor suppressor protein, has been linked to cell fate determination and/or maintenance of self-renewing populations in several epithelial tissues, including skin, mammary gland, and prostate (Yang et al. 2002). Furthermore, this gene is overexpressed in a variety of epithelial tumors including oral and skin squamous cell carcinomas (Westfall and Pietenpol 2004). p63 can be produced in at least six different isoforms. Initiation of transcription at two different promoters results in mRNAs coding for the TA-p63 and $\Delta \mathrm{N}$-p63 isoforms that contain and lack, respectively, an N-terminal transcription-activating domain. While $\Delta \mathrm{N}-\mathrm{p} 63$ can act as a dominant-negative suppressor of the TA isoform (Yang et al. 1998), it is also endowed with its own transcription-activating function (Dohn et al. 2001; King et al. 2003; Wu et al. 2003). Differential splicing of the TA-p63 and $\Delta$ N-p63 mRNAs leads in each case to the production of three different isoforms that contain

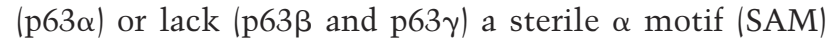
domain (Yang et al. 1998). TA-p63 $\alpha$ expression plays a key role in the transition from a simple to stratified epithelium during epidermal development (Koster et al. 2004). After birth, the major isoform expressed in keratinocytes is $\Delta \mathrm{N}-\mathrm{p} 63 \alpha$ (Yang et al. 1998). p63 is expressed in cells of the basal epidermal layer and hair follicles, and in the basal layers of the mammary gland and the prostate, while it is strongly down-modulated with differentiation (Yang et al. 1998; Di Como et al. 2002; Nylander et al. 2002).

The molecular basis for control of p63 expression is not known. Similarly, while elevated p63 expression can suppress differentiation (Ellisen et al. 2002; King et al. 2003, 2006; Koster et al. 2004), the underlying mechanisms have not been defined. Here, we show the existence of a complex negative feedback loop between Notch and p63 that controls the balance between keratinocyte self-renewal and differentiation. p63 expression is suppressed by Notch1 activation through a cell cycle-independent mechanism involving selective down-modulation of interferon-responsive genes. In turn, p63 functions as a modulator of Notch1-dependent transcription and function, with Hes-1 as a direct target gene.

\section{Results}

p63 expression is down-modulated by Notch1 activation in differentiation

While Notch1 activation triggers direct cell cycle withdrawal of mouse primary keratinocytes (Rangarajan et al. 2001), in keratinocytes of human origin it has less immediate effects, causing these cells to replicate for a limited number of times with a subsequent loss of clonogenic potential (Lowell et al. 2000; our unpublished observations). A comparative global analysis of gene expression was used to identify common Notch1 targets in mouse and human keratinocytes. Cells were infected with a recombinant adenovirus expressing a constitutive active form of Notch1 and GFP (Ad-NIC), versus an empty vector control virus expressing GFP alone (AdGFP). cRNA probes were hybridized in duplicate to oligonucleotide arrays and the Resourcerer software (available at http://pga.tigr.org/tigr-scripts/magic/rl.pl) was used to align microarray data for homologous cDNA sequences of the two species. Among these, 34 genes of known function were identified that were significantly up-regulated and 106 genes that were down-modulated by activated Notch 1 in both mouse and human keratinocytes. These genes were assigned to several functional categories, including control of transcription, signal transduction, and adhesion (Supplementary Table 1). Among down-regulated genes with a known or likely role in cell fate determination and/or differentiation was p63, a p53 homolog that has been linked to keratinocyte cell fate commitment and/or maintenance of self-renewing populations (McKeon 2004).

The major isoform expressed in keratinocytes after birth is $\Delta \mathrm{N}-\mathrm{p} 63 \alpha$ (Yang et al. 1998). Real-time RT-PCR confirmed that $\Delta \mathrm{N}$-p63 mRNA expression is strongly down-modulated by expression of activated Notch 1 in both mouse (Fig. 1A) and human keratinocytes (Fig. 1B), and similar down-modulation was found by immunoblotting at the protein level (Fig. 1C). Rather, low to undetectable levels of the other isoforms were found by RT-PCR with corresponding specific primers in these cells. For this reason, we refer throughout the paper to endogenous $\Delta \mathrm{N}-\mathrm{p} 63 \alpha$ generally as "p63" except where otherwise required.

To assess whether p63 expression is also down-modulated by activation of endogenous Notch receptors, two complementary approaches were taken. In the first, to mimic the up-regulation of Jagged expression that occurs in differentiating cells of the upper epidermal layers (Luo et al. 1997; Rangarajan et al. 2001; Nickoloff et al. 2002), keratinocytes were infected with an adenovirus express- 
A

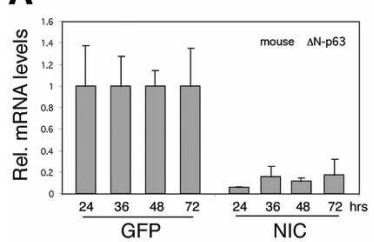

C

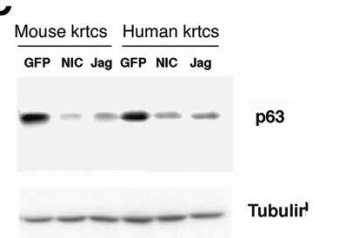

B

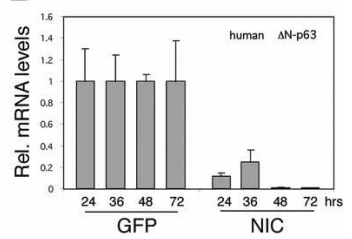

D

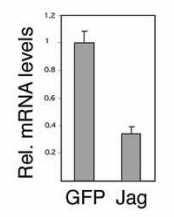

E

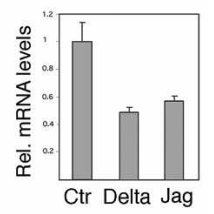

Figure 1. Negative control of $\Delta \mathrm{N}$-p63 expression by increased Notch signaling. $(A, B)$ Down-modulation of $\Delta$ N-p63 mRNA expression by activated Notch1. Primary mouse $(A)$ and human $(B)$ keratinocytes were infected with a recombinant adenovirus expressing the cytoplasmic-activated form of Notch1 (NIC) or a control GFP-expressing adenovirus (GFP) for the indicated times (in hours). p63 mRNA levels were quantified by real-time RT-PCR. Values are expressed as relative arbitrary units, after internal normalization for GAPDH (mouse keratinocytes) or $\beta$-actin (human keratinocytes) mRNA expression. $(C)$ Downmodulation of $\Delta \mathrm{N}-\mathrm{p} 63$ protein expression by activated Notch 1 . Primary mouse and human keratinocytes infected with the AdGFP (GFP), Ad-NIC (NIC), and Ad Jagged-1 (Jag) adenoviruses were analyzed for levels of p63 protein by immunoblotting with the corresponding antibodies. Immunoblotting for tubulin was used for equal loading control. (D) Down-modulation of p63 mRNA expression in response to increased Jagged 1 expression. Mouse keratinocytes were infected with an adenovirus expressing Jagged 1 (Jag) versus GFP control (GFP) for $24 \mathrm{~h}$ followed by p63 mRNA quantification as in the previous panels. $(E)$ Downmodulation of p63 mRNA expression by activation of endogenous Notch in response to Delta 1 or Jagged 1 exposure. Human keratinocytes were cocultured with control mouse NIH3T3 fibroblasts or fibroblasts expressing full-length Delta 1 or Jagged 1 for 48 h, followed by p63 mRNA quantification by RT-PCR with human-specific oligonucleotide primers.

ing the Jagged 1 ligand. p63 mRNA and protein were down-modulated significantly, as after direct expression of activated Notch1 (Fig. 1C,D). Alternatively, to induce activation of Notch receptors by ligand interaction with neighboring cells, human keratinocytes were cocultured for $48 \mathrm{~h}$ with either control mouse NIH3T3 fibroblasts or fibroblasts expressing the full-length Delta 1 or Jagged 1 ligands. Real-time RT-PCR analysis with human-specific oligonucleotide primers showed that p63 mRNA expression was suppressed significantly even in this case (Fig. 1E).

To assess whether the down-modulation of p63 expression in differentiation is Notch-dependent, we evaluated the consequences of deleting the endogenous Notch1 gene. In fact, while keratinocytes express both Notch1 and Notch2 receptors, conditional deletion of Notch1 is sufficient to alter their normal growth/differentiation program and promote carcinogenesis (Rangarajan et al. 2001; Nicolas et al. 2003). In primary keratino-

cytes where the Notch1 gene flanked by loxP sites was disrupted by Ad-Cre-mediated recombination, downregulation of p63 expression associated with differentiation occurred to a significantly lesser extent than in the controls (Fig. 2A), even though differentiation markers in these cultured cells are still induced (Rangarajan et al. 2001). In the intact epidermis in vivo, a keratinocytespecific deletion of the Notch1 gene induced by topical activation of a K5-CrePR1 transgene after birth (Mammucari et al. 2005) caused a substantial increase in p63 protein expression, especially pronounced in the upper epidermal layers (Fig. 2B). The increased p63 expression could be an early event triggered by deletion of the Notch1 gene or occur as a concomitant and/or secondary consequence of the epidermal hyperplasia. The activation of the K5-CrePR1 transgene by RU486 exposure used in the above experiments requires repeated days of treatment and further time to ensure efficient deletion of target genes (Mammucari et al. 2005). Therefore, to evaluate the early effects of Notch1 deletion, we used a second kind of mice, carrying the "floxed" Notch1 gene together with a constitutive K14-Cre transgene (K14Cresneo), which starts to be expressed around birth (Huelsken et al. 2001). Histological analysis of the skin of these mice revealed no differences in epidermal thickness and structure relative to K14-Cre negative controls until $7 \mathrm{~d}$ after birth, with a weak hyperplasia becoming detectable by $10 \mathrm{~d}$. In contrast, real-time RT-PCR analysis of epidermal RNA revealed a substantial up-regulation of $\mathrm{p} 63$ expression by the Notch $1^{-/-}$deletion already at 3 and $7 \mathrm{~d}$ after birth, with a further increase by $10 \mathrm{~d}$ (Fig. 2C).

Down-modulation of p63 expression could be due to an indirect consequence of Notch-induced growth arrest and/or be caused by key mediators of Notch function in these cells, like p21 $1^{\mathrm{WAF} 1 / \mathrm{Cip} 1}$ (Devgan et al. 2005) or HES/HERP family members (Iso et al. 2003). To directly assess these possibilities, keratinocytes were infected with recombinant adenoviruses expressing $\mathrm{p} 21^{\text {WAF1/Cip } 1 \text {, }}$ other cyclin-CDK inhibitors (p2 $7^{\text {Kip1 } 1}$ and $\left.\mathrm{p} 16^{\text {Ink4a }}\right)$, as well as various HES/HERP family members (Hes-1, Hey1, and Hey-2). No significant down-regulation of p63 mRNA levels was observed after expression of any of these proteins, in contrast to the Wnt4 gene which, as previously reported (Devgan et al. 2005), was negatively regulated by $\mathrm{p} 21^{\mathrm{WAF} 1 / \mathrm{Cip} 1}$ and/or Hes-1 expression (Fig. 2D).

Notch activation suppresses p63 expression through negative regulation of the interferon signaling pathway

To gain further insights into regulation of p63 expression, we analyzed a $10-\mathrm{kb}$ nucleotide sequence of the human and mouse $\Delta \mathrm{N}$-p 63 promoters for common transcription factor-binding motifs. The presence of multiple NF- $\mathrm{kB}$-binding sites as well as interferon-stimulated responsive elements (ISRE) (Levy et al. 1988) and binding sites for interferon-responsive factors (IRF) (Taniguchi et al. 2001) was found to be a characteristic of both promoters (Fig. 3A). While Notch activation is known to induce 
NF- $\kappa$ B activity in keratinocytes (Nickoloff et al. 2002), its possible impact on the interferon signaling pathway in this cell type, to our knowledge, has not been reported.

Activities of NF-кB and interferon-responsive reporters were induced and suppressed, respectively, by activated Notch1 expression in primary keratinocytes, consistent with induction of the NF- $\kappa \mathrm{B}$ and suppression of the interferon response pathways (Fig. 3B,C). In parallel with these findings, microarray analysis showed that a significant number of endogenous interferon-responsive genes are down-modulated in human primary keratinocytes as a consequence of activated Notch1 expression. However, this was a selective rather than generalized suppression of interferon-responsive genes, as many

Figure 2. Negative control of $\Delta \mathrm{N}-\mathrm{p} 63$ expression in differentiation as a function of endogenous Notch1, separately from cell cycle withdrawal and from $\mathrm{p} 21^{\mathrm{WAF} 1 / \mathrm{Cip} 1}$ and/or Hes-1 expression. (A) Differential down-modulation of $\Delta \mathrm{N}$-p63 expression upon induction of differentiation of wild-type versus Notch $1^{-/-}$ keratinocytes. Primary keratinocytes derived from mice with the Notch1 gene flanked by loxP sites (Rangarajan et al. 2001) were infected with a Cre recombinase-expressing adenovirus (Cre) (black bars), for deletion of the Notch1 gene, or with the Ad GFP control (GFP) (white bars). Three days after infection, cells were induced to differentiate by exposure to elevated extracellular calcium for $3 \mathrm{~d}$. p63 mRNA levels were quantified by real-time RT-PCR as in Figure 1. (B) Increased suprabasal p63 expression in the epidermis of mice with an induced deletion of the Notch 1 gene. Mice with the Notch 1 gene flanked by loxP sites and carrying a keratinocyte-specific K5-CrePR1 transgene versus control Cre-negative littermates were subjected to repeated topical treatments with RU486 for Cre activation as for our previous studies (Mammucari et al. 2005), starting at $5 \mathrm{~d}$ of age for five consecutive days. Dorsal skin sections from three mice per group, at $21 \mathrm{~d}$ of age, were analyzed by immunohistochemistry with antibodies against p63. Images are representative of a minimum of four independent fields per sections. $(C)$ Up-regulation of $\Delta \mathrm{N}$-p63 mRNA expression in the epidermis of mice at early times of Notch 1 deletion, prior to any detectable histological alterations. Mice homozygous for the Notch1/loxP gene and carrying the $\mathrm{K} 14 \mathrm{Cre} \Delta$ neo transgene (Huelsken et al. 2001) (black bars) versus K14Cre $\Delta$ neo negative controls (white bars) were sacrificed at the indicated days after birth. The epidermis was separated from the underlying dermis by a brief heat shock $\left(30 \mathrm{sec}\right.$ at $\left.60^{\circ} \mathrm{C}\right)$ and used for total RNA preparation. p63 mRNA quantification by real-time RT-PCR and GAPDH normalization were carried out as before. Parallel histological analysis of the same skin samples revealed no alterations caused by the Notch 1 deletion at 3 and $7 \mathrm{~d}$ after birth, with mild hyperplasia becoming detectable at $10 \mathrm{~d}$. The (Notch1/loxP$\mathrm{K} 14 \mathrm{Cre} \Delta$ neo) mice develop substantial skin alterations at later times, similar to those exhibited by mice with an inducible Notch1 deletion (Rangarajan et al. 2001; our unpublished observations). (D) Persistent p63 levels and down-modulation of Wnt4, in keratinocytes with increased $\mathrm{p} 21^{\mathrm{WAF} 1 / \mathrm{Cip} 1}$ and/or Hes-1 expression. Mouse primary keratinocytes were infected with recombinant adenoviruses expressing p21 WAF1/Cip1, p2 $7^{\text {Kip1 }}$, p16 ${ }^{\text {Ink4a }}$, Hes-1, Hey-1, Hey-2, or GFP control (multiplicity of infection: 100), followed by determination of p63 and Wnt4 mRNA levels by real-time RT-PCR with the corresponding specific primers. genes of this class were not affected by activated Notch1 expression, while some others were induced (Supplementary Table 2). Furthermore, the specific set of interferon-responsive genes that were found to be downmodulated in the mouse and human genes was different. Among the suppressed genes in human cells were the ones for IRF7, a key regulator of the interferon-dependent transcription cascade with oncogenic potential (Zhang and Pagano 2002; Honda et al. 2005), and Sp100, an essential component of nuclear bodies (NBs) (Fig. 3D; Moller et al. 2003), while in the mouse cells down-modulation was observed for IRF3, which physically interacts and functionally overlaps with IRF7 (Servant et al. 2002), and $\mathrm{IKK} \varepsilon$, a key kinase that positively regulates the interferon response (Fig. 3F; Fitzgerald et al. 2003). To assess whether down-modulation of these genes can also be caused by an increase in endogenous Notch signaling, human keratinocytes were cocultured for $48 \mathrm{~h}$ with control NIH3T3 mouse fibroblasts or fibroblasts expressing the full-length Jagged 1 ligand. RT-PCR analysis with oligonucleotide primers specific for the human genes showed that both IRF7 and Sp100 mRNA expression levels were significantly decreased in keratinocytes cocultured with Notch ligand-expressing fibroblasts (Fig. 3E). To evaluate the role of endogenous Notch signaling in control of the mouse genes, levels of IRF3 and IKK $\varepsilon$ expression were compared in the epidermis of mice with a Cre-induced deletion of the Notch1 gene versus matching controls with the undeleted gene. Deletion of the Notch1 gene resulted in a significant up-regulation of both IRF3 and IKKe genes (Fig. 3G), in parallel with the observed increase in p63 expression (Fig. 2C).

A

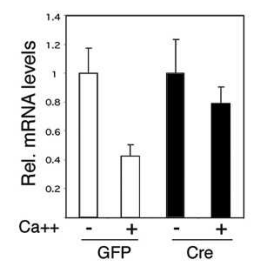

B

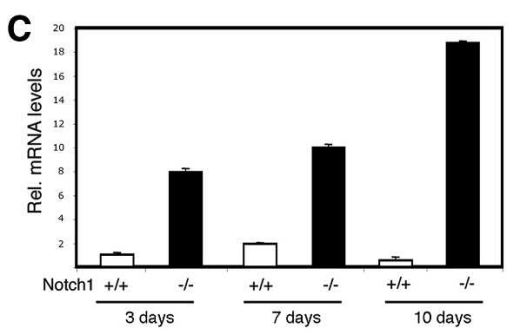

D

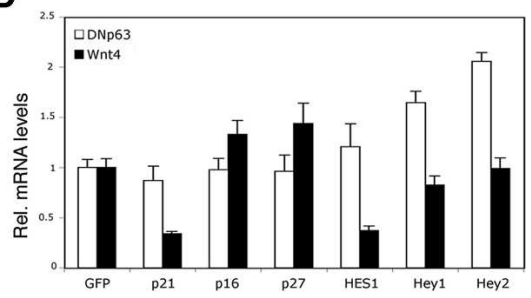


Figure 3. Interconnection between Notch, NF-кB, and interferon signaling pathways in control of p63 expression. (A) Schematic of the human and mouse $\Delta \mathrm{N}$-p63 promoters with positions of the NF-кB (triangles) and ISRE- and IRF-binding sites (diamonds). Ten kilobases of nucleotide sequence from the transcription initiation site were analyzed by MatInspector 7.4 (Genomatix Software) using an optimized matrix similarity and a core similarity of $>0.9$. (B) Induction of NF- $\mathrm{B}$ transcriptional activity by activated Notch1. Mouse primary keratinocytes were transfected with a NF-кB-responsive reporter (pNF-кB-luc) with or without increasing amounts of an expression plasmid for activated Notch1 as indicated. Cells were collected $48 \mathrm{~h}$ after transfection, and promoter activity values are expressed as arbitrary units using a Renilla reporter for internal normalization. Each condition was tested in triplicate wells, and the standard deviation is indicated. $(C)$ Suppression of interferon response transcriptional activity by activated Notch1 in mouse and human primary keratinocytes (left and right panels, respectively). Cells were transfected with a reporter plasmid carrying multiple copies of an ISRE (pHTSISRE-luc) with or without increasing amounts of an expression plasmid for activated Notch1 as indicated. Cells were collected $48 \mathrm{~h}$ after transfection, and promoter activity values were calculated using a Renilla reporter for internal normalization as in $B .(D)$ Down-modulation of endogenous interferon-responsive genes in human keratinocytes by activated Notch1 expression. Cells were infected with adenoviruses expressing activated Notch1 (NIC) or GFP-only control (GFP), followed by determination of mRNA expression levels of the indicated genes by real-time RT-PCR analysis. Values are expressed as relative arbitrary units, after internal normalization for $\beta$-actin mRNA expression. (E) Down-modulation of IRF7 and Sp100 gene expression by activation of endogenous Notch receptors. Primary human keratinocytes were cocultured with control or Jagged 1-expressing NIH-3T3 fibroblasts as in Figure 1E. IRF7 and Sp100 mRNA levels were determined by real-time RT-PCR as before. $(F)$ Down-modulation of IRF3 and IKK $\varepsilon$ expression in mouse primary keratinocytes by activated Notch1 expression. Cells were infected with adenoviruses expressing activated Notch1 (NIC) or GFP-only control (GFP), followed by determination of mRNA expression levels by real-time RT-PCR analysis. Values are expressed as relative arbitrary units, after internal normalization for GAPDH mRNA expression. (G) Up-regulation of IRF3 and IKK $\varepsilon$ expression in the epidermis of mice with an induced deletion of the Notch1 gene. Same RNA samples obtained from 10-d-old mice homozygous for the Notch1/loxP gene and carrying the K14Cre $\Delta$ neo transgene (-/-) versus K14Cre $\Delta$ neo negative controls $(+/+)$ and analyzed for p63 expression in Figure 2C, were analyzed for IRF3 and IKK $\varepsilon$ mRNA levels by real-time RT-PCR as in the previous panel. $(H)$ Induction of p63 expression by inhibition of NF-кB, with no counteracting effects on suppression by activated Notch1. Primary mouse keratinocytes were infected with recombinant

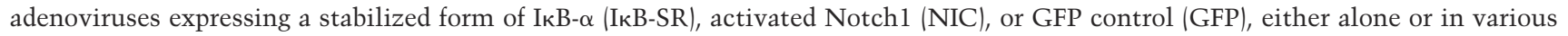
combinations as indicated. p63 mRNA levels were determined by real-time RT-PCR. $(I, J)$ Specific counteracting effects of IRF7 on suppression of p63 expression by activated Notch1. Primary mouse $(I)$ and human $(J)$ keratinocytes were infected with recombinant adenoviruses expressing IRF7 (IRF7), activated Notch1 (NIC), or GFP control (GFP), either alone or in various combinations as indicated. $\Delta$ N-p63 mRNA levels were determined by real-time RT-PCR. $(K)$ The same mouse keratinocyte RNA samples as in $J$ were analyzed for levels of Wnt4 expression by real-time RT-PCR with the corresponding specific primers. $(L)$ Down-modulation of p63 expression by knockdown of IRF7 and IRF3 expression. Human primary keratinocytes were transfected with siRNAs targeting the human IRF7 and IRF3 mRNA sequences, individually and in combination, in parallel with scrambled siRNAs control. Cells were analyzed at $48 \mathrm{~h}$ after transfection for levels of p63 expression by real-time RT-PCR. Similar results were obtained in two other independent experiments.

To assess whether the observed changes in either the $\mathrm{NF}-\mathrm{\kappa B}$ or interferon signaling pathways can account for down-modulation of p63 expression by Notch1 activation, keratinocytes were infected with recombinant adenoviruses expressing either a stabilized mutant form of $\mathrm{I}_{\kappa} \mathrm{B} \alpha$, which functions as an inhibitor of NF-кB function (Wang 
et al. 1999), or the full-length IRF7 protein, which, as mentioned, is a key downstream mediator of the interferon response (Zhang and Pagano 2002; Honda et al. 2005) and functionally overlaps with IRF3 (Servant et al. 2002). Expression of stabilized "super-repressor" IкB- $\alpha$ resulted in a substantial induction of p63 expression, indicating that the NF- $\mathrm{kB}$ pathway functions as a negative regulator of p63 already in keratinocytes under basal growing conditions (Fig. 3H). However, expression of the "super-repressor" I $\mathrm{KB} \alpha$ exerted no counteracting effects on down-modulation of $\mathrm{p} 63$ by activated Notch1. In contrast, infection of either human or mouse keratinocytes with the IRF7 adenovirus caused no significant increase in p63 expression by itself, but blocked the Notch-mediated down-modulation of this gene (Fig. 3I,J). These counteracting effects were specific for p63, as IRF7 did not affect the ability of activated Notch1 to suppress Wnt4, consistent with the different mechanism of regulation of this gene (Fig. 3K; Devgan et al. 2005).

Endogenous IRF7 is likely to act in concert with other interferon-responsive genes that are modulated by Notch in keratinocytes, in particular, IRF3. To assess this possibility, keratinocytes were treated with small interfering RNAs (siRNAs) specific for IRF7, either alone or in combination with siRNAs for IRF3. As shown in Figure $3 \mathrm{~L}$, p63 expression was consistently reduced by the concomitant knockdown of IRF7 and IRF3, although to a lesser extent than by activated Notch1. In contrast, no p63 down-modulation was caused by the knockdown of IRF7 alone, pointing to the importance of IRF7 overlapping functions with IRF3 and possibly other interferonresponsive genes in this setting.

\section{The pro-differentiation function of Notch is counteracted by $p 63$}

Biologically, the ability of Notch to restrict proliferation and promote differentiation may be suppressed by persistently elevated p63 expression. The clonogenic behavior of primary human keratinocytes provides a widely used assay for their proliferative potential (Rochat et al. 1994), which is negatively regulated by activation of the Notch pathway (Lowell et al. 2000). To test whether suppression of clonogenicity by Notch1 activation can be counteracted by p63, primary human keratinocytes were infected with a recombinant retrovirus expressing the $\Delta \mathrm{N}$-p63 $\alpha$ gene together with GFP (PINCO- $\Delta \mathrm{N}$-p63 $\alpha$ ) or a retrovirus expressing GFP alone (PINCO). In each case, GFP-positive keratinocytes were purified by sorting, and subsequently infected with the Ad-NIC or Ad-Jagged-1 viruses or control Ad-GFP. Cells were trypsinized and replated under sparse conditions soon after infection, before expression of adenovirally transduced proteins that could interfere with the attachment capability of cells. The long-term culture conditions used for these studies, growth in defined medium, do not allow for a distinction of holo-, para-, and mero-clones as classically defined used a feeder layer culture system (Barrandon and Green 1987). We note, however, that in previous studies on commitment of human keratinocytes toward differentia- tion by Notch activation, a parallel reduction in clonogenicity and "stem cell" clones was reported (Lowell et al. 2000). By our assays, we found no consistent difference in the colony-forming ability of keratinocytes infected with the p63 retrovirus versus control (Fig. 4; data not shown). However, while infection of control keratinocytes with the Ad-NIC or Ad-Jagged 1 viruses caused a drastic drop in the number of clonogenic cells, this reduction was much smaller in cells that had been previously transduced with the $\Delta \mathrm{N}$-p $63 \alpha$ retrovirus (Fig. 4), consistent with the proposed role of p63 in maintenance of the keratinocyte proliferative potential (McKeon 2004).

In mouse keratinocytes, increased Notch1 activity causes growth arrest through induction of $\mathrm{p} 21^{\text {WAF1/Cip } 1}$ expression by both direct and indirect RBP-Jк-dependent mechanisms (Rangarajan et al. 2001; Mammucari et al. 2005). In transient transfection assays of these cells, the ability of activated Notch 1 to induce the $2.4-\mathrm{kb}$ promoter of the p21 gene was suppressed by the concomitant overexpression of $\Delta \mathrm{N}-\mathrm{p} 63 \alpha$, in a dose-dependent fashion (Fig. 5A). This suppression may result from the demonstrated ability of $\Delta \mathrm{N}$-p $63 \alpha$ to bind directly to p53/ p63-binding sites in the $\mathrm{p} 21$ promoter (Westfall et al. 2003), thereby interfering with Notch-dependent p21 up-
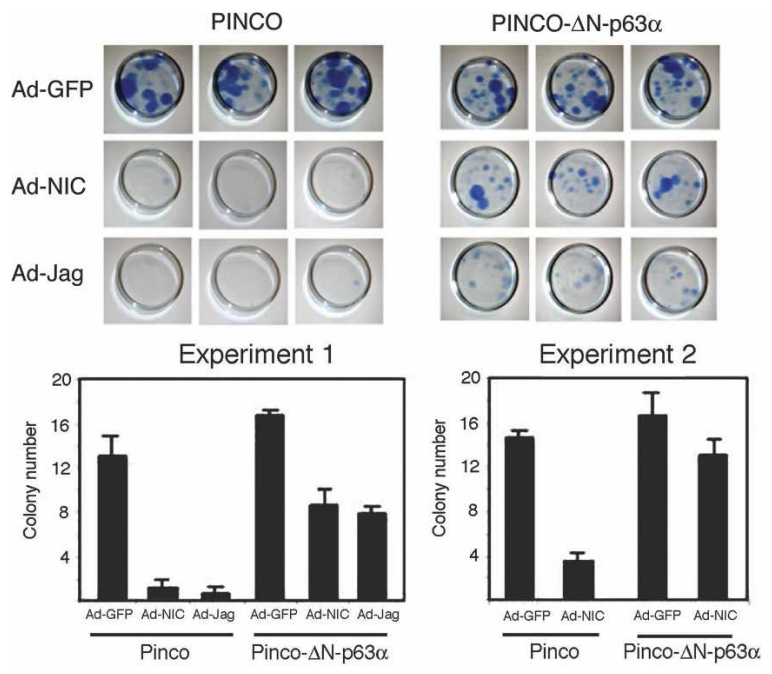

Figure 4. Counteracting effects of $\Delta \mathrm{N}-\mathrm{p} 63 \alpha$ on reduction of human keratinocyte proliferative potential by Notch activation. Early-passage primary human keratinocytes were infected with recombinant retroviruses expressing either a full-length $\Delta \mathrm{N}$-p $63 \alpha$ cDNA together with GFP (PINCO- $\Delta \mathrm{N}$-p $63 \alpha$ ) or GFP alone (PINCO). Three days after infection, GFP-positive cells were purified by sorting and replated. After $3 \mathrm{~d}$ of further cultivation, cells were infected with the Ad-GFP, Ad-NIC, or AdJagged 1 viruses. Cells were trypsinized, counted, and replated on triplicate dishes under sparse conditions $6 \mathrm{~h}$ after infection; that is, before expression of adenovirally transduced proteins that could interfere with the attachment capability of cells. After 3 wk of further cultivation, clonogenic growth was evaluated by staining of dishes and counting of macroscopically visible colonies (containing $>50$ cells). Shown is the quantification of this and a second independent experiment. 
Figure 5. Counteracting effects of $\Delta \mathrm{N}$ p $63 \alpha$ on the Notch-responsive p $21^{\text {WAF1/Cip } 1 \text {, }}$ involucrin, and Hes-1 genes. $(A-C)$ Suppression of Notch-dependent transcription in keratinocytes. Primary mouse keratinocytes were transiently transfected with reporter plasmids containing the $2.4-\mathrm{kb}$ promoter region of the p21 gene $(A)$, a minimal Notch-responsive region of the p21 promoter devoid of p53-binding sites but containing a fully conserved RBP-binding site (Rangarajan et al. 2001) (B), or the involucrin promoter (Rangarajan et al. 2001) $(C)$, plus/minus expression plasmids for activated Notch1 (NIC; $1 \mu \mathrm{g} /$ well), plus/ minus an expression vector for $\Delta \mathrm{N}-\mathrm{p} 63 \alpha$ in increasing amounts as indicated. In all cases, cells were collected $48 \mathrm{~h}$ after transfection, and promoter activity values are expressed as arbitrary units using a Renilla reporter for internal normalization. Each condition was tested in triplicate wells, and the standard deviation is indicated. $(D, E)$ Counteracting effects of p63 on endogenous Notch-responsive genes in cultured keratinocytes. Primary mouse keratinocytes were infected with adenoviruses expressing $\Delta \mathrm{N}-\mathrm{p} 63 \alpha(\Delta \mathrm{N}-\mathrm{p} 63 \alpha)$ and activated Notch1 (NIC), either individually or in combination. Ad-GFP (GFP) was used as a control and added to the Ad- $\Delta \mathrm{N}$-p63 $\alpha$ or Ad-NIC viruses when they were used alone, to ensure that in all cases cells received the same amount of viral particles (total multiplicity of infection: 100). Cells were analyzed by either immunoblotting with antibodies against the indicated proteins $(D)$ or real-time RT-PCR with primers specific for the indicated genes $(E)$. $(F)$ Counteracting effects of p63 on endogenous Notch-responsive genes in the skin in vivo. The epidermis from two "gene-switch" TAp63 $\alpha$ transgenic mice, in which TAp63 expression was induced in the epidermis by topical application of RU486 (Koster et al. 2004), and two transgenic-negative littermate controls were obtained by laser capture microdissection, followed by total RNA preparation and a single round of linear amplification. Expression of the indicated genes was assessed by real-time RT-PCR with the corresponding specific primers.

regulation. However, induction of a minimal p21 promoter region containing the binding site for Notch/RBP but not for p53/p63 (Rangarajan et al. 2001) was also suppressed by $\Delta \mathrm{N}-\mathrm{p} 63 \alpha$, to a similar extent as the fulllength promoter (Fig. 5B). Induction of the promoter for involucrin, a keratinocyte differentiation marker gene, by activated Notch1 (Rangarajan et al. 2001) was also blocked by $\Delta \mathrm{N}$-p63 $\alpha$ expression with a greater potency than the p21 promoter (Fig. 5C). As with $\Delta \mathrm{N}-\mathrm{p} 63 \alpha$, exogenous expression of the TA-p63 $\alpha$ isoform exerted similar inhibitory effects on both $\mathrm{p} 21$ and involucrin promoter activity (data not shown).

To probe into the regulation of endogenous Notchresponsive genes, mouse keratinocytes were infected with recombinant adenoviruses expressing activated Notch1 and $\Delta \mathrm{N}$-p $63 \alpha$ either individually or in combination. Immunoblot analysis showed that basal levels of p21 and involucrin were reduced by elevated p63 expression. More importantly, induction of these proteins by activated Notch1 was totally blocked in the p63-overexpressing cells (Fig. 5D). Similarly, the basal level of expression of Hes-1, a well-known Notch target (Iso et al. 2003), was suppressed by increased $\Delta \mathrm{N}-\mathrm{p} 63 \alpha$ expression, and its induction by activated Notch1 was blocked (Fig. $5 \mathrm{E})$. Expression of the Wnt4 gene, which is down-modu- lated as a consequence of Notch activation in keratinocytes (Devgan et al. 2005), was also oppositely regulated in cells with elevated p63 expression (Fig. 5E).

In the epidermis of transgenic mice in vivo, increased expression of TA-p63 $\alpha$ causes aberrant differentiation (Koster et al. 2004). To test whether even under these conditions, increased p63 expression interferes with expression of Notch-responsive genes, the epidermis of TA-p $63 \alpha$ transgenics and littermate controls was captured by laser microdissection, followed by RNA preparation and linear amplification. As predicted by the experiment with cultured cells, Hes-1 expression was significantly suppressed in the epidermis of $\mathrm{p} 63$ transgenics versus control, and similar differences were found in levels of p21 and involucrin expression (Fig. 5F).

p63 is a selective modulator of Notch effectors, with the Hes-1 gene as a direct negative target

The keratinocyte terminal differentiation program involves the sequential induction of markers of overlying epidermal layers. While induction of these markers usually occurs in a coordinated fashion, they can be dissociated both genetically and pharmacologically (Dotto 1999). Like p21 and involucrin, keratin 1 (K1) is induced 
by Notch1 activation in keratinocytes (Rangarajan et al. 2001). Surprisingly, we found that this marker, unlike p21 and involucrin, was not suppressed but slightly induced by increased p63 expression, with a strong synergistic effect with activated Notch1 itself (Fig. 5D). This suggested that p63 may not function as a general suppressor of Notch-dependent transcription, but may selectively suppress the expression and/or function of some Notch effectors while inducing others. In fact, increased p63, while suppressing basal and Notch-induced Hes-1 levels, caused an induction of Hey-1 and Hey-2 expression, two well-studied HERP family members (Iso et al. 2003), even in the absence of Notch activation (Fig. 6A). In keratinocytes with concomitant p63 and Notch1 expression, the Hey-2 gene was also superinduced (Fig.

A
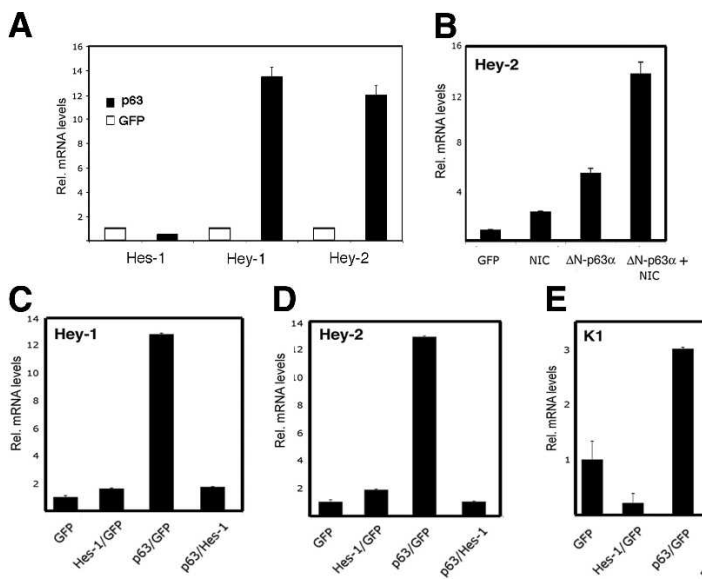

E

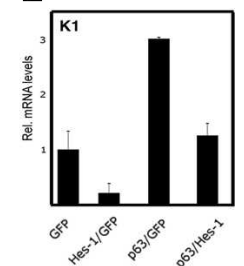

Figure 6. p63 as a differential modulator of Hes-1 versus Hey1, Hey-2, and K1 genes. (A) Concomitant induction of Hey-1 and Hey-2 expression with suppression of Hes-1 by increased p63 expression. Mouse primary keratinocytes were infected with a $\Delta \mathrm{N}$-p63 $\alpha$ (black bars) or GFP control (white bars) adenovirus. Total RNA was prepared from cells at $30 \mathrm{~h}$ after infection, followed by real-time RT-PCR analysis using specific oligonucleotide primers for the indicated genes. Values are expressed as relative arbitrary units, after internal normalization for GAPDH mRNA expression. (B) Superinduction of Hey-2 expression by concomitant p63 and activated Notch1 expression. Primary mouse keratinocytes were infected with adenoviruses expressing $\Delta \mathrm{N}$-p $63 \alpha(\Delta \mathrm{N}-\mathrm{p} 63 \alpha)$ and activated Notch1 (NIC), either individually or in combination as in Figure 5E. Ad-GFP (GFP) was used as a control and added to the Ad- $\Delta \mathrm{N}$-p $63 \alpha$ or Ad-NIC viruses when they were used alone, to ensure that in all cases cells received the same amount of viral particles. Cells were analyzed by real-time RT-PCR for Hey-2 mRNA levels. Similar analysis for Hey-1 expression indicated that this gene, unlike Hey-2, is not superinduced by concomitant p63 and NIC expression (data not shown). $(C, D)$ Down-modulation of Hes-1 is required for Hey-1 and Hey-2 induction by p63. Mouse primary keratinocytes were infected with Hes-1 and $\Delta \mathrm{N}$-p $63 \alpha$ adenoviruses and Ad-GFP control either alone or in combination as indicated. Hey-1 and Hey-2 expression was determined by real-time RTPCR analysis as in the previous experiments. (E) Down-modulation of Hes-1 is required for K1 induction by p63. The same cells as in the previous experiment were analyzed for levels of keratin 1 (K1) expression by real-time RT-PCR analysis with the corresponding specific primers as indicated.
6B). Hes/HERP family members are subject to reciprocal negative regulation (Iso et al. 2003), raising the possibility that induction of Hey-1 and/or Hey-2 by p63 may depend on Hes-1 suppression. To assess this possibility, cells were infected with Hes-1 and p63 adenoviruses either alone or in combination. Increased Hes-1 expression caused by itself no down-modulation of Hey-1 or Hey-2 mRNA levels, and even an increase. However, the strong induction of Hey-1 and Hey-2 expression by p63 was totally prevented by Hes-1 (Fig. 6C,D). To assess whether this regulatory loop can also impinge on the effects of p63 on differentiation, the same cells were analyzed for levels of keratin 1 expression. Increased Hes-1 expression caused by itself a suppression of $\mathrm{K} 1$ expression and was sufficient to block the induction of this gene by p63 (Fig. 6E).

The above findings raised the possibility that Hes-1 is a direct key target gene of p63 in keratinocytes. To establish whether modulation of this gene coincides with the earliest gene expression events triggered by increased p63 expression, we chose a global analysis of gene expression approach with keratinocytes expressing a $\Delta \mathrm{N}$ p $63 \alpha$ protein fused to an estrogen receptor domain and maintained under basal conditions in an inactive form in the cytoplasm. Total RNA was prepared at early time points after p63 activation by tamoxifen treatment, followed by RNA probe preparation and microarray hybridization. Among the earliest suppressed genes was Hes-1, while levels of Hey-1 and Hey-2 at these early times remained unaffected (Fig. 7A).

Analysis of the nucleotide sequence of the mouse Hes-1 promoter (a $10-\mathrm{kb}$ region from the transcription start site) revealed a predicted p53/p63-binding site at position -7944 base pairs (bp) from the transcription start site (Fig. 7B), while no such sites were found in the Hey-1 and Hey-2 promoters. To assess whether p63 binds to the endogenous Hes-1 promoter, chromatin immunoprecipitation (ChIP) assays were performed with antibodies against mouse p63 followed by scanning of the sequential region of the Hes- 1 promoter by PCR amplification with corresponding primers. As shown in Figure 7C, specific binding of endogenous p63 could be readily demonstrated at the expected position of the Hes-1 promoter, with no binding elsewhere.

To assess whether the Hes-1 gene is under negative control of endogenous p63, primary keratinocytes were transfected with two different siRNAs for the coding region of mouse p63 versus a scrambled siRNA control. This approach caused $>80 \%-90 \%$ reduction in mRNA and p63 protein levels by $2-3 \mathrm{~d}$ after transfection; in cells expressing activated Notch1, the p63 siRNAs caused a further substantial p63 reduction (Fig. 8A-C). The p63 knockdown resulted in a substantially increased expression of Hes-1 already in cells under basal conditions, with a superinduction in response to activated Notch1 (Fig. 8D). p21 expression was similarly up-regulated in cells with p63 knockdown, while expression of Wnt4 was reduced (Fig. 8E,F). Importantly, expression of $\mathrm{K} 1$ was also negatively regulated by the p63 knockdown in opposition to the effects of Notch1 (Fig. 8G), mirroring 


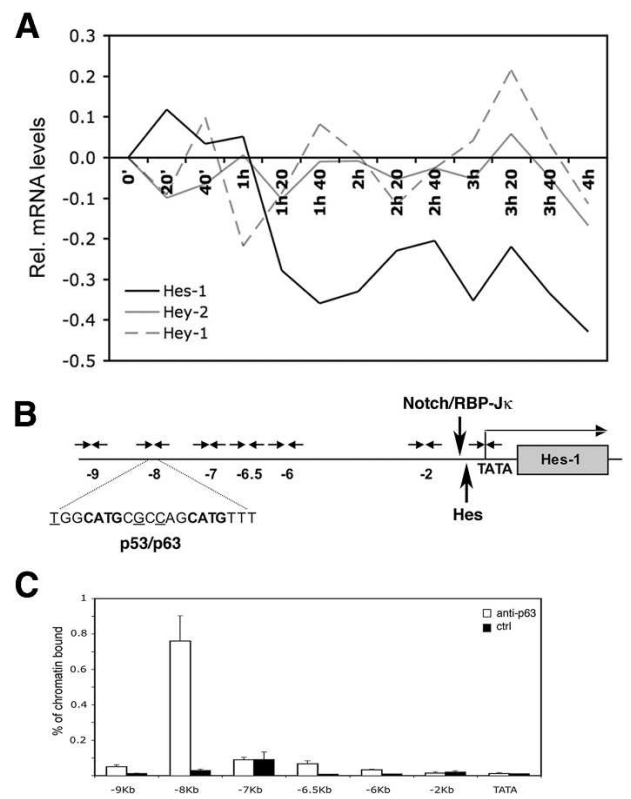

Figure 7. Hes-1 as a direct p63 target gene. (A) Expression profile of Hes-1 (black solid bar), Hey-1 (gray dotted line), and Hey-2 (gray solid bar) at early times upon induction of p63 activity. Primary mouse keratinocytes were infected with a retrovirus carrying an ER-p63 fusion protein (PINCO ER-p63) or empty vector control (PINCO) and subsequently treated with $20 \mathrm{nM}$ tamoxifen for the indicated times. Total RNA was used for cDNA and fluorescent RNA probe preparation followed by hybridization to oligonucleotide microarrays (Mouse Expression Arrays from Affymetrix 430 A 2.0). Data were analyzed using the dChip program ( $\mathrm{Li}$ and Wong 2001), and values are expressed as changes in relative mRNA levels in the ER-p63-expressing versus control keratinocytes. $(B)$ Map of the Hes-1 promoter. The predicted p53/p63-binding site is indicated together with its precise nucleotide sequence: Bold nucleotides correspond to the core nucleotide sequence required for p53-p63 binding (Barbieri et al. 2005; Ihrie et al. 2005 and references therein), while underlined nucleotides are possible mismatches. The approximate position of the two Notch/RBP-JK (-90 and -75) (Jarriault et al. 1995) and four Hes-binding sites (positions -165, -151, -132 , and +16 ) (Takebayashi et al. 1994) is also indicated, together with that of the oligonucleotide primers used for the ChIP analysis (arrows). (C) Specific binding of endogenous p63 to the Hes-1 promoter. Primary mouse keratinocytes under growing conditions were processed for ChIP with antibodies specific for p63 (white bars) or unrelated anti-ERK1 antibodies as control (black bars), followed by real-time PCR amplification of various regions of the Hes-1 promoter indicated in the schematic above. Unprecipitated chromatin preparations were similarly analyzed and used as "input" control. The amount of precipitated DNA was calculated relative to the total input chromatin, and expressed as the percentage of the total according to the following formula (Frank et al. 2001): $\%$ total $=2^{\Delta \mathrm{Ct}} \times 5$, where $\Delta \mathrm{Ct}=\mathrm{Ct}($ input $)-\mathrm{Ct}($ immunoprecipitation). (Ct) Cycle threshold.

the opposite up-regulation of this marker by elevated p63 expression. The $\Delta \mathrm{N}-\mathrm{p} 63 \gamma$ isoform is also expressed in keratinocytes, although to a much lesser extent than $\Delta \mathrm{N}-\mathrm{p} 63 \alpha(\sim 10 \%$, as measured by real-time RT-PCR). By use of siRNAs specific for this isoform, we observed none of the effects seen with siRNAs for total $\Delta \mathrm{N}$-p63 or specific for $\Delta \mathrm{N}-\mathrm{p} 63 \alpha$ (data not shown).

\section{Discussion}

We have shown here that $\mathrm{p} 63$ is a negative target gene of Notch 1 activation in keratinocytes, both in vitro and in vivo, while, in turn, p63 acts as a selective negative regulator of Notch-dependent transcription and function. p63 plays an essential role in development of the skin and other epithelial tissues (Mills et al. 1999; Yang et al. 1999), and more specifically in the transition between the simple and stratified epithelium of the epidermis (Koster et al. 2004) and associated establishment of asymmetric cell division (Lechler and Fuchs 2005). However, p63 is likely also to play a very significant role after birth. Elevated expression of this gene has been associated with keratinocyte populations with high self-renewal potential and a variety of epithelial tumors, including squamous cell carcinomas (Parsa et al. 1999; Pellegrini et al. 2001; Westfall and Pietenpol 2004). Deletion of the p63 gene promotes senescence (Keyes et al. 2005), while its increased expression suppresses differentiation (King et al. 2003, 2006; Koster et al. 2004).

$\Delta \mathrm{N}-\mathrm{p} 63 \alpha$ is the main isoform expressed in keratinocytes after birth (Yang et al. 1998). Little is known about the mechanism responsible for down-modulation of this gene with differentiation. We have shown here that this is dependent on Notch1 function both in vitro and in vivo. Negative regulation of $\mathrm{p} 63$ by Notch 1 activation is likely to occur through a cell-type-specific mechanism, as the opposite effect was reported in NIH3T3 fibroblasts (Ross and Kadesch 2004). It is not an indirect consequence of growth arrest and is not caused by key mediators of Notch function in keratinocytes, like HES/HERP family members (Iso et al. 2003) or p21 $1^{\text {WAF1/Cip } 1 \text { (Ranga- }}$ rajan et al. 2001; Devgan et al. 2005). Several NF-кBbinding sites are present in both mouse and human promoters for $\Delta \mathrm{N}-\mathrm{p} 63$. NF- $\kappa \mathrm{B}$ can suppress expression of selected target genes (Delhalle et al. 2004). Since NF-кB activity is induced in keratinocyte differentiation (Seitz et al. 1998; van Hogerlinden et al. 1999) as well as by Notch activation (Nickoloff et al. 2002), an attractive possibility is that suppression of p63 by Notch involves NF- $\mathrm{B}$ activation. Expression of stabilized super-repressor IкB- $\alpha$ resulted in strong induction of $\mathrm{p} 63$ expression, indicating that p63 is, indeed, negatively regulated by NF-кB, already in keratinocytes under basal growing conditions. ChIP experiments also showed that in these cells the NF-кB p65-RelA subunit, which has been specifically implicated in negative control of keratinocyte proliferation (Zhang et al. 2004), binds specifically to the proximal region of the p63 promoter, with little or no binding of other NF- $\mathrm{kB}$ subunits (Supplementary Fig. 1). However, the stabilized IкB- $\alpha$ failed to counteract the Notch suppressing effects on p63 expression, indicating that, if NF- $\mathrm{KB}$ is involved, Notch-dependent suppression occurs through a mechanism that is not blocked by the ІкB- $\alpha$ super-repressor, like the noncanonical NF-кB p100-p52 pathway (Senftleben et al. 2001). Another 
A

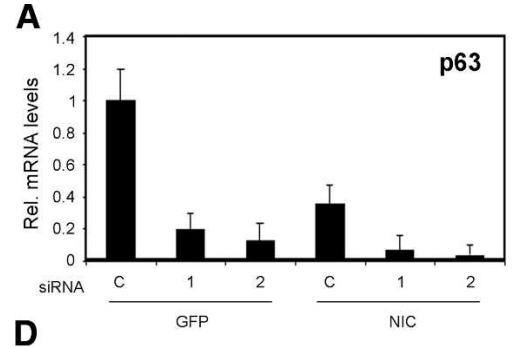

D

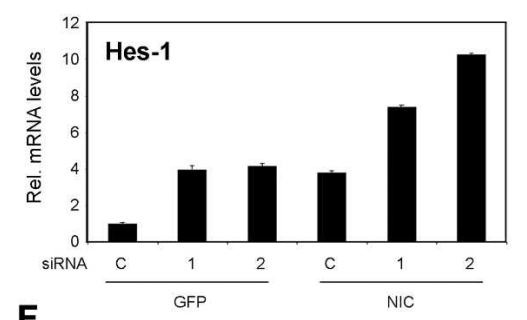

F

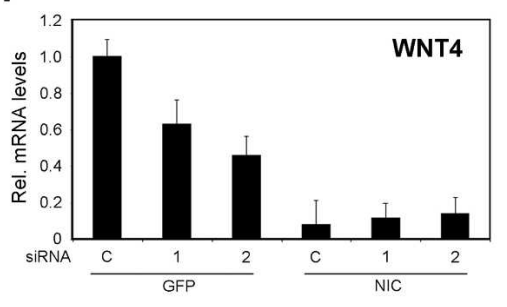

B

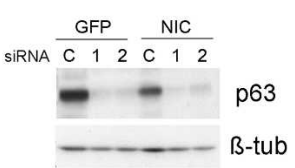

C

E
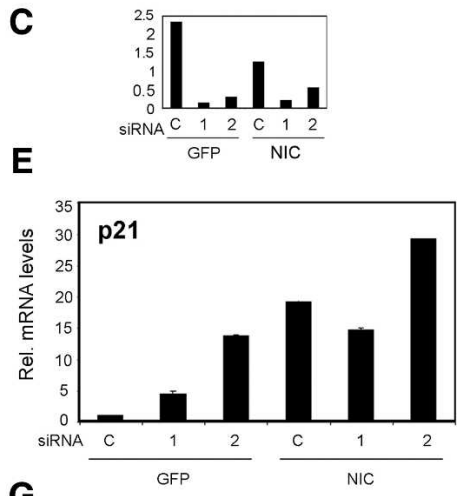

G

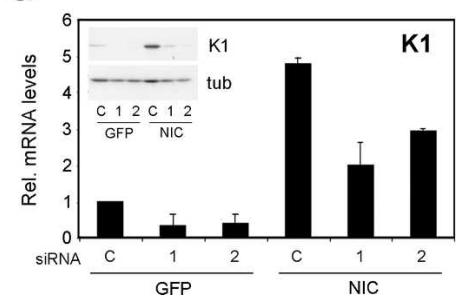

Figure 8. Control of Hes-1 and other Notch-responsive genes by endogenous p63. $(A-C)$ Knockdown of endogenous p63 expression by siRNA technology. Primary mouse keratinocytes were transfected with siRNAs targeting two distinct regions of the mouse $\Delta \mathrm{N}$-p63 $\alpha$ mRNA sequence (1 and 2) or scrambled siRNAs control. Parallel cultures were infected with the Ad-GFP and Ad-NIC viruses at $24 \mathrm{~h}$ after siRNA transfection as indicated. Cells were analyzed at 48 $\mathrm{h}$ after transfection for levels of p63 expression by real-time RT-PCR $(A)$ or immunoblotting with the corresponding antibodies $(B)$. $(C)$ The immunoblotting results were also quantified by densitometric scanning of the autoradiograph and normalization for $\beta$-tubulin levels. $(D-G)$ Up-regulation of Hes-1 and p21 expression and down-regulation of Wnt4 and $\mathrm{K} 1$ expression as a consequence of p63 knockdown. Primary mouse keratinocyte cultures treated as above were analyzed for expression levels of the indicated genes by real-time RT-PCR analysis and, for K1, also by immunoblotting ( $G$ insert). mechanism could be the direct association of activated Notch1 with NF- $\mathrm{B}$ components in the nucleus, as indicated by a very recent report for T cells (Shin et al. 2006). Besides NF-кB-binding sites, both mouse and human $\Delta$ Np63 promoters contain several interferon-responsive elements, with a potentially significant similarity with the $\beta$-interferon enhancer, where a synergistic multiprotein complex is formed (Thanos and Maniatis 1995) by NF- $\kappa$ B subunits and IRF3/IRF7 proteins, two key downstream mediators of the interferon response (Servant et al. 2002; Zhang and Pagano 2002). Consistent with an involvement of this latter pathway, overexpression of IRF7, while by itself not increasing p63 expression, was sufficient to block the Notch-dependent suppression. Importantly, IRF7 did not affect modulation of Wnt4, another Notch target controlled by a different mechanism (Devgan et al. 2005).

To our knowledge, modulation of the interferon signaling pathway by Notch activation has not been previously reported, with the possible exception of Hes proteins binding to Stat3 and enhancing its Jak-dependent phosphorylation (Kamakura et al. 2004). Induction of the interferon transcriptional response involves a relatively well-characterized sequence of events, beginning with activation of the TAK 1 and IKK $\varepsilon$ kinases and consequent phosphorylation and homo- and heterodimerization of IRF3 with IRF7 followed by nuclear translocation of these factors and activation of gene expression (Taniguchi et al. 2001). However, much less is known about the mechanisms that negatively regulate this pathway. Importantly, we have found that Notch activation in keratinocytes causes selective suppression of some inter- feron-responsive genes, while inducing others (Supplementary Table 2), pointing to the existence of a novel mechanism for the fine tuning of the interferon response, which may be of particular significance for modulation of growth-differentiation control as opposed to the antiviral function. Several of the interferon-responsive genes under negative Notch control in keratinocytes have been previously implicated in positive growth control, apoptosis, and/or tumorigenesis (e.g., see Ghosh et al. 2001; Carpten et al. 2002; Wasylyk et al. 2002; Zhang and Pagano 2002), with an impact that is likely to extend to keratinocytes. We note in particular the down-modulation of Sp100, a key component of nuclear bodies involved in chromatin control (Moller et al. 2003), which parallels the opposite up-regulation of PML, another nuclear body component, in cells with loss of p63 expression (Bernassola et al. 2005; Keyes et al. 2005). While we have focused on IRF7 for direct functional studies and shown that IRF7 overexpression is sufficient to relieve Notch-dependent suppression of expression of p63, the endogenous IRF7 protein is likely to function in concert with other interferon-responsive genes in regulation of p63 expression. In fact, knockdown of endogenous IRF7 caused down-modulation of p63 expression, but this only in concomitance with knockdown of IRF3, and the reduction of p63 levels by the concomitant IRF7 and IRF3 knockdown was less than that caused by activated Notch1 expression. The fact that in mouse keratinocytes, as opposed to the human cells, Notch signaling causes down-modulation of IRF3 rather than IRF7 further illustrates this functional overlap. 
While down-regulated by Notch activation, p63 in turn, counteracts the ability of Notch to restrict growth and promote differentiation, with antagonistic effects on Notch-responsive genes both in vitro and in vivo. $\Delta \mathrm{N}$ p $63 \alpha$ is the main isoform expressed in this cell type after birth, and is endowed with both transcription activating (Dohn et al. 2001; King et al. 2003; Wu et al. 2003) and repressing (Yang et al. 1998) functions, the latter being ascribed to a C-terminal domain that is shared with the TA-p63 $\alpha$ isoform (Serber et al. 2002). Our finding that transcription of Notch-responsive genes is suppressed in keratinocytes by both isoforms is consistent with previous reports of their shared inhibitory effects on differentiation (King et al. 2003; Koster et al. 2004). Importantly, however, p63 does not function as a general negative regulator of differentiation-related genes, as it blocks expression of involucrin, a terminal differentiation marker of the granular and upper layers, while up-regulating keratin 1, a marker of early entry into differentiation that is also under positive Notch control. We note that the p63 protein is expressed not only in the basal epidermal layer but also in a significant fraction of immediately overlying cells where $\mathrm{K} 1$ is expressed, suggesting that p63 can have both antagonistic and synergistic effects with Notch in differentiation.

Consistent with this possibility, we have found that p63 is a selective modulator of Notch1-dependent transcription, with the Hes-1 gene as one of its direct negative targets, and with other genes, like Hey-1 and Hey-2 family members and the K1 marker, being induced, rather than suppressed, through a mechanism dependent on Hes-1 down-modulation. Negative regulation of Hes- 1 occurs at very early times of activation of a p63-ER fusion protein, and endogenous p63 binds to the Hes-1 promoter with knockdown of this protein resulting in increased Hes- 1 expression. Hes-1, in turn, is a key regulator of p21 (Mammucari et al. 2005), Wnt4 (Devgan et al. 2005), and, as we have shown here, K1 expression in keratinocytes. Besides Notch and p63, the Hes-1 gene is itself under control of other differentiation signaling pathways in these cells, like calcineurin/NFAT (Mammucari et al. 2005). Besides impinging on this complex intracellular regulatory mechanism, p63 has also the potential of modulating expression of the Jagged 1 and/or 2 ligands (Sasaki et al. 2002; Wu et al. 2003), thereby extending its effects on Notch signaling to neighboring cells.

In summary, our findings are consistent with a model of dynamic equilibrium in the skin among keratinocyte populations at various stages of commitment toward differentiation (Okuyama et al. 2004a). The Notch-p63 cross-talk that we have uncovered is likely to have a key role in this sequence of events, with p63 playing a dual function of suppressing Notch signaling in epidermal cells with high self-renewal potential, while synergizing with other specific aspects of Notch function involved in the early stages of differentiation (Fig. 9). Down-modulation of p63 expression by increased Notch signaling could then be a signal for later stages to occur. The Hes-1 gene in this context can be viewed as a relay for this dual
A
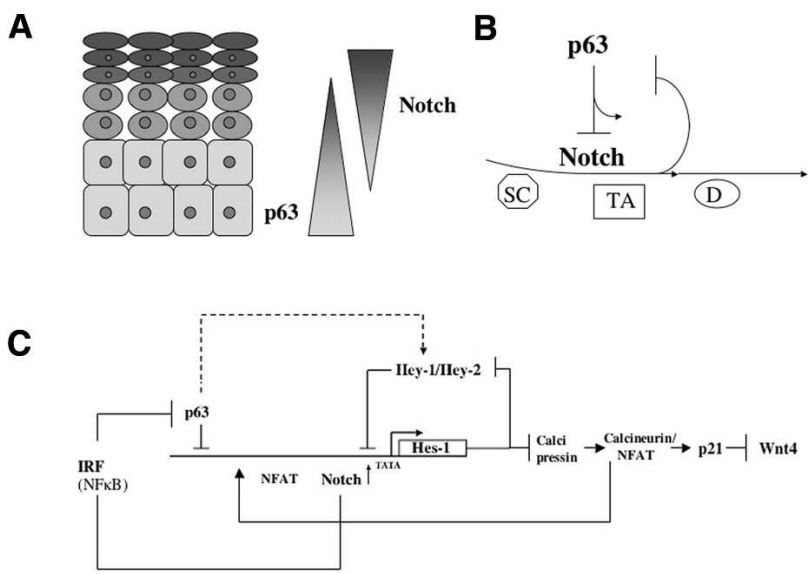

Figure 9. Dynamic model of Notch-p63 cross-regulation in control of keratinocyte self-renewal versus differentiation. $(A)$ Diagram of the epidermis illustrating the inverse gradient of p63 expression versus Notch activity in the lower versus upper epidermal layers, which is likely to result, at least in part, from their reciprocal negative regulation. $(B)$ Scheme illustrating the dual function of p63 in suppressing Notch signaling in epidermal cells with high self-renewal potential, while synergizing with other specific aspects of Notch function involved in the early stages of differentiation. (SC) Putative stem cell populations; (TA) transient amplifying cells. Down-modulation of p63 expression by increased Notch signaling could then be a signal for later stages to occur. (D) Differentiated cells. (C) The Hes-1 gene as a relay for multiple feedback mechanisms in the integrated control of keratinocyte self-renewal versus differentiation. While Hes-1 is a direct target of p63, with its down-modulation leading to an induction of Hey-1 and Hey-2 family members, we have found that Hey $1 / 2$ overexpression, in turn, downmodulates Hes-1 levels, providing a possible reinforcement mechanism for the negative regulation of Hes-1 by p63. The other signaling pathways that converge on control of the Hes-1 gene and its downstream involvement in regulating calcineurin/NFAT activity and $\mathrm{p} 21$ and Wnt 4 expression are discussed in the text.

biological response integrating inputs from the Notch, p63, and other distinct pathways. An important implication of this model is that persistently elevated p63 expression as a result of decreased Notch signaling, and/ or in tumor development, could lead to an arrest at an intermediate stage of differentiation rather than an earlier block of stem cell commitment.

\section{Materials and methods}

\section{Cells and viruses}

Primary mouse and human keratinocytes were cultured as previously described (Rangarajan et al. 2001; Talora et al. 2002). NIH3T3 fibroblasts expressing full-length Delta 1 (Trifonova et al. 2004) and Jagged 1 (Small et al. 2003) were cocultured, in parallel with NIH3T3 controls, with human primary keratinocytes for $48 \mathrm{~h}$ as described (Lowell et al. 2000). Adenoviruses expressing Cre and activated Notch1 (Rangarajan et al. 2001), Hes-1 (Sriuranpong et al. 2002), and Hey-1 and Hey-2 (Mammucari et al. 2005) were previously described. The adenovirus expressing stabilized ІкB- $\alpha$ was obtained from the Virus Vector 
Core, University of North Carolina at Chapel Hill. The adenovirus expressing Jagged-1 was constructed by cre/lox recombination, by inserting a rat Jagged- 1 cDNA, modified to encode a HA-tag at the C terminus, into the pAd-lox shuttle vector (Hardy et al. 1997). The mouse cDNA for $\Delta \mathrm{N}$-p63 $\alpha$ was obtained by RT-PCR cloning in frame with the Flag epitope in pCMV2FLAG (Sigma) at the NotI-XbaI sites. Proper expression was confirmed by transient transfection in 293 cells and immunoblotting with p63 pan-antibodies (Santa Cruz) and Flag antibodies (Sigma M2). cDNAs for $\Delta \mathrm{N}-\mathrm{p} 63 \alpha$ and IRF7 (Zhang and Pagano 1997) were inserted at the BamHI site of the pAdTRACK vector, followed by homologous recombination into the Ad-Easyl backbone (He et al. 1998), using the same conditions for recombinant adenovirus production and purification as previously described (Rangarajan et al. 2001).

For retrovirus production, the Flag-tagged $\Delta \mathrm{Np} 63 \alpha \mathrm{cDNA}$ insert was then subcloned into the BamHI site of the PINCO retroviral vector (Nocentini et al. 1997). Expression of the retrovirally transduced p63 cDNA was verified by immunoblotting of infected human and mouse keratinocytes with anti-Flag and anti-p63 antibodies. For the retrovirus expressing inducible p63, a modified estrogen receptor ligand-binding domain (ER) (Littlewood et al. 1995) was cloned in frame between the Flag epitope and the $\Delta \mathrm{Np} 63 \alpha$ cDNA lacking the first ATG and inserted into the HindIII-NotI sites under the control of the CMV promoter in the PINCO retroviral vector (Nocentini et al. 1997).

\section{Promoter activity assays}

Expression plasmids for TA-p63 $\alpha$ (Koster et al. 2004) and for activated Notch1 (Capobianco et al. 1997) and reporters for the p21, involucrin, (Rangarajan et al. 2001), and Hes-1 promoter (Jarriault et al. 1995) and for NF-кB activity (Cheng and Baltimore 1996) were previously described. The reporter for interferon response activity was obtained from Biomyx Technology. Transient transfection promoter activity assays were performed as previously described (Rangarajan et al. 2001; Talora et al. 2002), using cotransfection of the individual reporters with a TK-Renilla reporter for internal normalization. Total quantities of plasmid DNA were kept constant by adding appropriate amounts of empty vectors without inserts. Transfected cells were harvested at $48 \mathrm{~h}$ after transfection, and relative luciferase activities were normalized for Renilla luciferase activity. All conditions were tested in triplicate wells.

\section{Analysis of gene expression}

Poly $(\mathrm{A})^{+}$mRNAs $(2-5 \mu \mathrm{g})$ from cells under various conditions were used as template for double-stranded cDNA preparations with T7-(dT) ${ }_{24}$ oligonucleotide primers for the first-strand reaction. The resulting cDNAs were used for preparation of biotinlabeled antisense cRNA and further used for hybridization to Affymetrix "gene chips" according to the manufacturer's recommendation, as previously described (Okuyama et al. 2004b).

For real-time RT-PCR, total RNA preparations (1-2 $\mu \mathrm{g}$ ) were used in an RT reaction with random primers, followed by realtime PCR with gene-specific primers, using an Icycler IQ RealTime Detection System (Bio-Rad) according to the manufacturer's recommendations, with SYBR Green (Applied Biosystems) for detection. Each sample was tested in triplicate, and results were normalized using amplification of the same cDNAs with mouse GAPDH or human $\beta$-actin primers.

\section{ChIP assays}

Approximately $3 \times 10^{6}$ mouse keratinocytes were fixed with $1 \%$ formaldehyde in growth media at $37^{\circ} \mathrm{C}$ for $10 \mathrm{~min}$. ChIPs were carried out as previously described (Rangarajan et al. 2001) using rabbit anti-p63 antibodies (H-137; Santa Cruz Biotechnology) or anti-ERK-1 (K23; Santa Cruz Biotechnology) antibodies as control. The following primers were used for real-time PCR amplifications of various regions of the HES- 1 promoter: TATA-box, TCTTCCTCCCATTGGCTGAA and ACGGCTCGTGTGAA ACTTCC; $-1.5-\mathrm{kb}$ region, AAGGCAGCAACCTCCATCTCT and TTCTCACACTCGGATTCCCTG; $-2-\mathrm{kb}$ region, TCTG GCGTTCCATCACAAAG and GTGGTGCTTCCTTGACTG CAT; -6-kb region, AAGCCTCTGTTTTCCACCCC and AA GCCCAGACGGTGCTAAGA; -6.5-kb region, CTTCCAGCC TCAGAGGGATTT and ATATGATATGCGCTGGGCCT; -7 $\mathrm{kb}$ region, AGTGGCTTGGCTTAGCTTGG and AAGTACAG GCAGCCTGGCC; -8-kb region, CCAGCATGTTTCCAGAG AGCT and TGGCTGCTATCCTAGAAGGCC; -9-kb region, TATCTCGCTCCTTCCCACGT and TGCAGGTACAAAG CAATTCCC.

\section{Laser capture microdissection and RNA preparation}

Three-week-old "gene-switch" TAp63 $\alpha$ transgenics and control littermates (Koster et al. 2004) were treated topically for $5 \mathrm{~d}$ with $100 \mu \mathrm{g}$ of RU486, dissolved in $70 \%$ ethanol. Frozen skin sections ( $9 \mu \mathrm{m}$ thick) were used for Laser Capture Microdissection (LCM) with an AutoPix Automated Laser Capture Microdissection System as previously described (Mammucari et al. 2005). Reagents and protocols used in the laser capture procedures were from Arcturus. RNA was extracted from each sample with the PicoPure RNA isolation kit and subjected to one round of linear amplification using the RiboAmp RNA amplification kit (ENZO Life Science), followed by RT-PCR analysis with gene-specific primers.

\section{siRNA transfection and analysis}

Primary keratinocytes of either human or mouse origin were transfected with $200 \mathrm{nM}$ siRNAs for validated human IRF7 (SI00448672) and IRF3 (SI00026411) mRNAs (from QIAGEN) or two distinct regions of the mouse $\Delta \mathrm{N}-\mathrm{p} 63 \alpha$ mRNA (siRNA \#1 sense, UUAGGGCAUCGUUUCACAACCUCGG; antisense, CCGAGGUUGUGAAACGAUGCCCUA A; siRNA \#2 sense, UCACAACAGUCCUGUACAAUUUCAU; antisense, AUGA AAUUGUACAGGACUGUUGUGA) and corresponding control scrambled siRNAs using Lipofectamine 2000 following the manufacturer's recommendations. Cells were analyzed $48 \mathrm{~h}$ after transfection by either RT-PCR or Western blot as indicated.

\section{Acknowledgments}

We thank Drs. D. Ball, L. Liaw, and J. Pagano for their gifts of the Ad HES-1, Ad-HEY-1, and Ad-HEY-2 viruses and IRF7 expression plasmids, respectively. We are grateful to Drs. Diego Di Bernardo and Mukesh Bansal for their help with analysis of the time series microarrays, and Sabrina Streuli and Vikram Rajashekara for skillful technical support. This work was supported by NIH Grants AR39190, CA16038, and CA73796 and a grant from the Swiss National Foundation to G.P.D.; in part by the Cutaneous Biology Research Center through the Massachusetts General Hospital/Shiseido Co. Ltd. Agreement; by grants from the Italian Telethon Foundation (TCMP14TELB), the Ministry of Instruction, University and Research (MIUR FIRB), and the European Union (LSHG-CT-2004-511990) to C.M.; and by the National Foundation for Ectodermal Dysplasia (NFED, to G.P.D. and C.M.). 


\section{References}

Artavanis-Tsakonas, S., Rand, M.D., and Lake, R.J. 1999. Notch signaling: Cell fate control and signal integration in development. Science 284: 770-776.

Barbieri, C.E., Perez, C.A., Johnson, K.N., Ely, K.A., Billheimer, D., and Pietenpol, J.A. 2005. IGFBP-3 is a direct target of transcriptional regulation by $\Delta \mathrm{Np} 63 \alpha$ in squamous epithelium. Cancer Res. 65: 2314-2320.

Barrandon, Y. and Green, H. 1987. Three clonal types of keratinocyte with different capacities for multiplication. Proc. Natl. Acad. Sci. 84: 2302-2306.

Bernassola, F., Oberst, A., Melino, G., and Pandolfi, P.P. 2005. The promyelocytic leukaemia protein tumour suppressor functions as a transcriptional regulator of p63. Oncogene 24: 6982-6986.

Capobianco, A.J., Zagouras, P., Blaumueller, C.M., ArtavanisTsakonas, S., and Bishop, J.M. 1997. Neoplastic transformation by truncated alleles of human NOTCH1/TAN1 and NOTCH2. Mol. Cell. Biol. 17: 6265-6273.

Carpten, J., Nupponen, N., Isaacs, S., Sood, R., Robbins, C., Xu, J., Faruque, M., Moses, T., Ewing, C., Gillanders, E., et al. 2002. Germline mutations in the ribonuclease $\mathrm{L}$ gene in families showing linkage with HPC1. Nat. Genet. 30: 181184.

Cheng, G. and Baltimore, D. 1996. TANK, a co-inducer with TRAF2 of TNF- and CD 40L-mediated NF-кB activation. Genes \& Dev. 10: 963-973.

Chu, J., Jeffries, S., Norton, J.E., Capobianco, A.J., and Bresnick, E.H. 2002. Repression of activator protein-1-mediated transcriptional activation by the Notch-1 intracellular domain. $J$. Biol. Chem. 277: 7587-7597.

Davis, R.L. and Turner, D.L. 2001. Vertebrate hairy and Enhancer of split related proteins: Transcriptional repressors regulating cellular differentiation and embryonic patterning. Oncogene 20: 8342-8357.

Delhalle, S., Blasius, R., Dicato, M., and Diederich, M. 2004. A beginner's guide to NF-кB signaling pathways. Ann. N.Y. Acad. Sci. 1030: 1-13.

Devgan, V., Mammucari, C., Millar, S.E., Brisken, C., and Dotto, G.P. 2005. p21WAF1/Cip1 is a negative transcriptional regulator of Wnt4 expression downstream of Notch1 activation. Genes \& Dev. 19: 1485-1495.

Di Como, C.J., Urist, M.J., Babayan, I., Drobnjak, M., Hedvat, C.V., Teruya-Feldstein, J., Pohar, K., Hoos, A., and CordonCardo, C. 2002. p63 expression profiles in human normal and tumor tissues. Clin. Cancer Res. 8: 494-501.

Dohn, M., Zhang, S., and Chen, X. 2001. p63 $\alpha$ and $\Delta$ Np63 $\alpha$ can induce cell cycle arrest and apoptosis and differentially regulate p53 target genes. Oncogene 20: 3193-3205.

Dotto, G.P. 1999. Signal transduction pathways controlling the switch between keratinocyte growth and differentiation. Crit. Rev. Oral Biol. Med. 10: 442-457.

Ellisen, L.W., Ramsayer, K.D., Johannessen, C.M., Yang, A., Beppu, H., Minda, K., Oliner, J.D., McKeon, F., and Haber, D.A. 2002. REDD1, a developmentally regulated transcriptional target of p63 and p53, links p63 to regulation of reactive oxygen species. Mol. Cell 10: 995-1005.

Fitzgerald, K.A., McWhirter, S.M., Faia, K.L., Rowe, D.C., Latz, E., Golenbock, D.T., Coyle, A.J., Liao, S.M., and Maniatis, T. 2003. IKK $\varepsilon$ and TBK1 are essential components of the IRF3 signaling pathway. Nat. Immunol. 4: 491-496.

Frank, S.R., Schroeder, M., Fernandez, P., Taubert, S., and Amati, B. 2001. Binding of c-Myc to chromatin mediates mitogen-induced acetylation of histone $\mathrm{H} 4$ and gene activation. Genes \& Dev. 15: 2069-2082.
Ghosh, A., Sarkar, S.N., Rowe, T.M., and Sen, G.C. 2001. A specific isozyme of $2^{\prime}-5^{\prime}$ oligoadenylate synthetase is a dual function proapoptotic protein of the Bcl-2 family. J. Biol. Chem. 276: 25447-25455.

Hardy, S., Kitamura, M., Harris-Stansil, T., Dai, Y., and Phipps, M.L. 1997. Construction of adenovirus vectors through Crelox recombination. J. Virol. 71: 1842-1849.

He, T.C., Zhou, S., da Costa, L.T., Yu, J., Kinzler, K.W., and Vogelstein, B. 1998. A simplified system for generating recombinant adenoviruses. Proc. Natl. Acad. Sci. 95: 25092514.

Honda, K., Yanai, H., Negishi, H., Asagiri, M., Sato, M., Mizutani, T., Shimada, N., Ohba, Y., Takaoka, A., Yoshida, N., et al. 2005. IRF-7 is the master regulator of type-I interferondependent immune responses. Nature 434: 772-777.

Huelsken, J., Vogel, R., Erdmann, B., Cotsarelis, G., and Birchmeier, W. 2001. $\beta$-Catenin controls hair follicle morphogenesis and stem cell differentiation in the skin. Cell 105: 533545.

Ihrie, R.A., Marques, M.R., Nguyen, B.T., Horner, J.S., Papazoglu, C., Bronson, R.T., Mills, A.A., and Attardi, L.D. 2005. Perp is a p63-regulated gene essential for epithelial integrity. Cell 120: 843-856.

Iso, T., Kedes, L., and Hamamori, Y. 2003. HES and HERP families: Multiple effectors of the Notch signaling pathway. I. Cell. Physiol. 194: 237-255.

Jarriault, S., Brou, C., Logeat, F., Schroeter, E.H., Kopan, R., and Israel, A. 1995. Signalling downstream of activated mammalian Notch. Nature 377: 355-358.

Kamakura, S., Oishi, K., Yoshimatsu, T., Nakafuku, M., Masuyama, N., and Gotoh, Y. 2004. Hes binding to STAT3 mediates crosstalk between Notch and JAK-STAT signalling. Nat. Cell Biol. 6: 547-554.

Keyes, W.M., Wu, Y., Vogel, H., Guo, X., Lowe, S.W., and Mills, A.A. 2005. p63 deficiency activates a program of cellular senescence and leads to accelerated aging. Genes \& Dev. 19: 1986-1999.

King, K.E., Ponnamperuma, R.M., Yamashita, T., Tokino, T., Lee, L.A., Young, M.F., and Weinberg, W.C. 2003. $\Delta$ Np63 $\alpha$ functions as both a positive and a negative transcriptional regulator and blocks in vitro differentiation of murine keratinocytes. Oncogene 22: 3635-3644.

King, K.E., Ponnamperuma, R.M., Gerdes, M.J., Tokino, T., Yamashita, T., Baker, C.C., and Weinberg, W.C. 2006. Unique domain functions of $\mathrm{p} 63$ isotypes that differentially regulate distinct aspects of epidermal homeostasis. Carcinogenesis 27: 53-63.

Koster, M.I., Kim, S., Mills, A.A., DeMayo, F.J., and Roop, D.R. 2004. p63 is the molecular switch for initiation of an epithelial stratification program. Genes \& Dev. 18: 126-131.

Lai, E.C. 2002. Keeping a good pathway down: Transcriptional repression of Notch pathway target genes by CSL proteins. EMBO Rep. 3: 840-845.

Lechler, T. and Fuchs, E. 2005. Asymmetric cell divisions promote stratification and differentiation of mammalian skin. Nature 437: 275-280.

Levy, D.E., Kessler, D.S., Pine, R., Reich, N., and Darnell Jr., J.E. 1988. Interferon-induced nuclear factors that bind a shared promoter element correlate with positive and negative transcriptional control. Genes \& Dev. 2: 383-393.

Li, C. and Wong, W.H. 2001. Model-based analysis of oligonucleotide arrays: Expression index computation and outlier detection. Proc. Nat1. Acad. Sci. 98: 31-36.

Littlewood, T.D., Hancock, D.C., Danielian, P.S., Parker, M.G., and Evan, G.I. 1995. A modified oestrogen receptor ligandbinding domain as an improved switch for the regulation of 
heterologous proteins. Nucleic Acids Res. 23: 1686-1690.

Lowell, S., Jones, P., Le Roux, I., Dunne, J., and Watt, F.M. 2000. Stimulation of human epidermal differentiation by DeltaNotch signalling at the boundaries of stem-cell clusters. Curr. Biol. 10: 491-500.

Luo, B., Aster, J.C., Hasserjian, R.P., Kuo, F., and Sklar, J. 1997. Isolation and functional analysis of a cDNA for human Jagged2, a gene encoding a ligand for the Notch1 receptor. Mol. Cell. Biol. 17: 6057-6067.

Mammucari, C., di Vignano, A.T., Sharov, A.A., Neilson, J., Havrda, M.C., Roop, D.R., Botchkarev, V.A., Crabtree, G.R., and Dotto, G.P. 2005. Integration of Notch 1 and calcineurin/NFAT signaling pathways in keratinocyte growth and differentiation control. Dev. Cell 8: 665-676.

McKeon, F. 2004. p63 and the epithelial stem cell: More than status quo? Genes \& Dev. 18: 465-469.

Mills, A.A., Zheng, B., Wang, X.J., Vogel, H., Roop, D.R., and Bradley, A. 1999. p63 is a p53 homologue required for limb and epidermal morphogenesis. Nature 398: 708-713.

Moller, A., Sirma, H., Hofmann, T.G., Staege, H., Gresko, E., Ludi, K.S., Klimczak, E., Droge, W., Will, H., and Schmitz, M.L. 2003. Sp100 is important for the stimulatory effect of homeodomain-interacting protein kinase-2 on p53-dependent gene expression. Oncogene 22: 8731-8737.

Mumm, J.S. and Kopan, R. 2000. Notch signaling: From the outside in. Dev. Biol. 228: 151-165.

Nickoloff, B.J., Qin, J.Z., Chaturvedi, V., Denning, M.F., Bonish, B., and Miele, L. 2002. Jagged-1 mediated activation of notch signaling induces complete maturation of human keratinocytes through NF-кB and PPAR $\gamma$. Cell Death Differ. 9: 842855.

Nicolas, M., Wolfer, A., Raj, K., Kummer, J.A., Mill, P., Van Noort, M., Hui, C.C., Clevers, H., Dotto, G.P., and Radtke, F. 2003. Notch 1 functions as a tumor suppressor in mouse skin. Nat. Genet. 33: 416-421.

Nocentini, G., Giunchi, L., Ronchetti, S., Krausz, L.T., Bartoli, A., Moraca, R., Migliorati, G., and Riccardi, C. 1997. A new member of the tumor necrosis factor/nerve growth factor receptor family inhibits $\mathrm{T}$ cell receptor-induced apoptosis. Proc. Natl. Acad. Sci. 94: 6216-6221.

Nylander, K., Vojtesek, B., Nenutil, R., Lindgren, B., Roos, G., Zhanxiang, W., Sjostrom, B., Dahlqvist, A., and Coates, P.J. 2002. Differential expression of p63 isoforms in normal tissues and neoplastic cells. J. Pathol. 198: 417-427.

Okuyama, R., LeFort, K., and Dotto, G.P. 2004a. A dynamic model of keratinocyte stem cell renewal and differentiation: Role of the p21WAF1/Cip1 and Notch1 signaling pathways. J. Investig. Dermatol. Symp. Proc. 9: 248-252.

Okuyama, R., Nguyen, B.C., Talora, C., Ogawa, E., di Vignano, A.T., Lioumi, M., Chiorino, G., Tagami, H., Woo, M., and Dotto, G.P. 2004b. High commitment of embryonic keratinocytes to terminal differentiation through a Notch1caspase 3 regulatory mechanism. Dev. Cell 6: 551-562.

Oswald, F., Tauber, B., Dobner, T., Bourteele, S., Kostezka, U., Adler, G., Liptay, S., and Schmid, R.M. 2001. p300 acts as a transcriptional coactivator for mammalian Notch-1. Mol. Cell. Biol. 21: 7761-7774.

Parsa, R., Yang, A., McKeon, F., and Green, H. 1999. Association of p63 with proliferative potential in normal and neoplastic human keratinocytes. J. Invest. Dermatol. 113: 1099-1105.

Pellegrini, G., Dellambra, E., Golisano, O., Martinelli, E., Fantozzi, I., Bondanza, S., Ponzin, D., McKeon, F., and De Luca, M. 2001. p63 identifies keratinocyte stem cells. Proc. Natl. Acad. Sci. 98: 3156-3161.

Petcherski, A.G. and Kimble, J. 2000. Mastermind is a putative activator for Notch. Curr. Biol. 10: R471-R473.
Rangarajan, A., Talora, C., Okuyama, R., Nicolas, M., Mammucari, C., Oh, H., Aster, J.C., Krishna, S., Metzger, D., Chambon, P., et al. 2001. Notch signaling is a direct determinant of keratinocyte growth arrest and entry into differentiation. EMBO J. 20: 3427-3436.

Rochat, A., Kobayashi, K., and Barrandon, Y. 1994. Location of stem cells of human hair follicles by clonal analysis. Cell 76: 1063-1073.

Ross, D.A. and Kadesch, T. 2004. Consequences of Notch-mediated induction of Jagged1. Exp. Cell Res. 296: 173-182.

Sasaki, Y., Ishida, S., Morimoto, I., Yamashita, T., Kojima, T., Kihara, C., Tanaka, T., Imai, K., Nakamura, Y., and Tokino, T. 2002. The p53 family member genes are involved in the Notch signal pathway. J. Biol. Chem. 277: 719-724.

Seitz, C.S., Lin, Q., Deng, H., and Khavari, P.A. 1998. Alterations in NF- $\mathrm{BB}$ function in transgenic epithelial tissue demonstrate a growth inhibitory role for NF-кB. Proc. Nat1. Acad. Sci. 95: 2307-2312.

Senftleben, U., Cao, Y., Xiao, G., Greten, F.R., Krahn, G., Bonizzi, G., Chen, Y., Hu, Y., Fong, A., Sun, S.C., et al. 2001. Activation by IKK $\alpha$ of a second, evolutionary conserved, NFкB signaling pathway. Science 293: 1495-1499.

Serber, Z., Lai, H.C., Yang, A., Ou, H.D., Sigal, M.S., Kelly, A.E., Darimont, B.D., Duijf, P.H., Van Bokhoven, H., McKeon, F., et al. 2002. A C-terminal inhibitory domain controls the activity of p63 by an intramolecular mechanism. Mol. Cell. Biol. 22: 8601-8611.

Servant, M.J., Tenoever, B., and Lin, R. 2002. Overlapping and distinct mechanisms regulating IRF-3 and IRF-7 function. $J$. Interferon Cytokine Res. 22: 49-58.

Shin, H.M., Minter, L.M., Cho, O.H., Gottipati, S., Fauq, A.H., Golde, T.E., Sonenshein, G.E., and Osborne, B.A. 2006. Notch1 augments NF-кB activity by facilitating its nuclear retention. EMBO I. 25: 129-138.

Small, D., Kovalenko, D., Soldi, R., Mandinova, A., Kolev, V., Trifonova, R., Bagala, C., Kacer, D., Battelli, C., Liaw, L., et al. 2003. Notch activation suppresses fibroblast growth factor-dependent cellular transformation. I. Biol. Chem. 278: $16405-16413$.

Sriuranpong, V., Borges, M.W., Strock, C.L., Nakakura, E.K., Watkins, D.N., Blaumueller, C.M., Nelkin, B.D., and Ball, D.W. 2002. Notch signaling induces rapid degradation of achaete-scute homolog 1. Mol. Cell. Biol. 22: 3129-3139.

Takebayashi, K., Sasai, Y., Sakai, Y., Watanabe, T., Nakanishi, S., and Kageyama, R. 1994. Structure, chromosomal locus, and promoter analysis of the gene encoding the mouse helixloop-helix factor HES-1. Negative autoregulation through the multiple N box elements. J. Biol. Chem. 269: 5150-5156.

Talora, C., Sgroi, D.C., Crum, C.P., and Dotto, G.P. 2002. Specific down-modulation of Notch1 signaling in cervical cancer cells is required for sustained HPV-E6/E7 expression and late steps of malignant transformation. Genes \& Dev. 16: 2252-2263.

Taniguchi, T., Ogasawara, K., Takaoka, A., and Tanaka, N. 2001. IRF family of transcription factors as regulators of host defense. Annu. Rev. Immunol. 19: 623-655.

Thanos, D. and Maniatis, T. 1995. Virus induction of human IFN $\beta$ gene expression requires the assembly of an enhanceosome. Cell 83: 1091-1100.

Trifonova, R., Small, D., Kacer, D., Kovalenko, D., Kolev, V., Mandinova, A., Soldi, R., Liaw, L., Prudovsky, I., and Maciag, T. 2004. The non-transmembrane form of Deltal, but not of Jagged1, induces normal migratory behavior accompanied by fibroblast growth factor receptor 1-dependent transformation. J. Biol. Chem. 279: 13285-13288.

van Hogerlinden, M., Rozell, B.L., Ahrlund-Richter, L., and 
Nguyen et al.

Toftgard, R. 1999. Squamous cell carcinomas and increased apoptosis in skin with inhibited Rel/nuclear factor-кB signaling. Cancer Res. 59: 3299-3303.

Wang, C.Y., Cusack Jr., J.C., Liu, R., and Baldwin Jr., A.S. 1999. Control of inducible chemoresistance: Enhanced anti-tumor therapy through increased apoptosis by inhibition of NF- $\mathrm{kB}$. Nat. Med. 5: 412-417.

Wasylyk, C., Schlumberger, S.E., Criqui-Filipe, P., and Wasylyk, B. 2002. Sp100 interacts with ETS-1 and stimulates its transcriptional activity. Mol. Cell. Biol. 22: 2687-2702.

Westfall, M.D. and Pietenpol, J.A. 2004. p63: Molecular complexity in development and cancer. Carcinogenesis 25: 857864.

Westfall, M.D., Mays, D.J., Sniezek, J.C., and Pietenpol, J.A. 2003. The Delta Np63 $\alpha$ phosphoprotein binds the p21 and 14-3-3 $\sigma$ promoters in vivo and has transcriptional repressor activity that is reduced by Hay-Wells syndrome-derived mutations. Mol. Cell. Biol. 23: 2264-2276.

Wu, L., Aster, J.C., Blacklow, S.C., Lake, R., Artavanis-Tsakonas, S., and Griffin, J.D. 2000. MAML1, a human homologue of Drosophila mastermind, is a transcriptional co-activator for NOTCH receptors. Nat. Genet. 26: 484-489.

Wu, G., Nomoto, S., Hoque, M.O., Dracheva, T., Osada, M., Lee, C.C., Dong, S.M., Guo, Z., Benoit, N., Cohen, Y., et al. 2003. $\Delta \mathrm{Np} 63 \alpha$ and TAp $63 \alpha$ regulate transcription of genes with distinct biological functions in cancer and development. Cancer Res. 63: 2351-2357.

Yang, A., Kaghad, M., Wang, Y., Gillett, E., Fleming, M.D., Dotsch, V., Andrews, N.C., Caput, D., and McKeon, F. 1998. p63, a p53 homolog at 3q27-29, encodes multiple products with transactivating, death-inducing, and dominant-negative activities. Mol. Cell 2: 305-316.

Yang, A., Schweitzer, R., Sun, D., Kaghad, M., Walker, N., Bronson, R.T., Tabin, C., Sharpe, A., Caput, D., Crum, C., et al. 1999. p63 is essential for regenerative proliferation in limb, craniofacial and epithelial development. Nature 398: 714718.

Yang, A., Kaghad, M., Caput, D., and McKeon, F. 2002. On the shoulders of giants: p63, p73 and the rise of p53. Trends Genet. 18: 90-95.

Zhang, L. and Pagano, J.S. 1997. IRF-7, a new interferon regulatory factor associated with Epstein-Barr virus latency. Mol. Cell. Biol. 17: 5748-5757.

. 2002. Structure and function of IRF-7. J. Interferon Cytokine Res. 22: 95-101.

Zhang, J.Y., Green, C.L., Tao, S., and Khavari, P.A. 2004. NF-кB RelA opposes epidermal proliferation driven by TNFR1 and JNK. Genes \& Dev. 18: 17-22. 


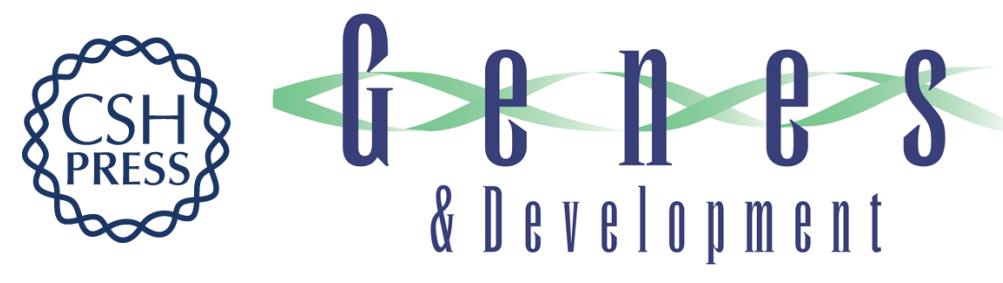

\section{Cross-regulation between Notch and p63 in keratinocyte commitment to differentiation}

Bach-Cuc Nguyen, Karine Lefort, Anna Mandinova, et al.

Genes Dev. 2006, 20:

Access the most recent version at doi:10.1101/gad.1406006

\section{Supplemental http://genesdev.cshlp.org/content/suppl/2006/04/06/20.8.1028.DC1 Material}

References This article cites 81 articles, 38 of which can be accessed free at: http://genesdev.cshlp.org/content/20/8/1028.full.html\#ref-list-1

\section{License}

Email Alerting

Receive free email alerts when new articles cite this article - sign up in the box at the top Service

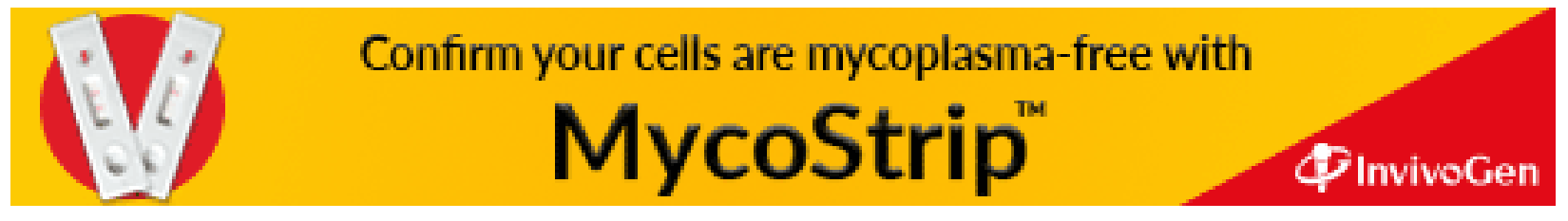

